\title{
К ВОПРОСАМ КОМПЛЕКСНЫХ И СТРУКТУРИРОВАННЫХ СПОСОБОВ ОЦЕНКИ ОТРАСЛЕВЫХ РИСКОВ "
}

\author{
(C) 2020 Шнайдер О. В. \\ кандидат экономических наук, доцент Департамента бизнес-аналитики \\ Финансовый университет при Правительстве Российской Федерации, Россия, Москва \\ E-mail: OVSHnajder@fa.ru
}

(C) 2020 Антонова О.В.

кандидат экономических наук, доцент Департамента бизнес-аналитики

Финансовый университет при Правительстве Российской Федерации, Россия, Москва

E-mail: olgavit01@yandex.ru

(c) 2020 Мельникова Л. А.

кандидат экономических наук, доцент Департамента бизнес-аналитики

Финансовый университет при Правительстве Российской Федерации, Россия, Москва

E-mail: lamelnikova@mail.ru

Вопросы комплексных и структурированных способов оценки отраслевых рисков являются одними из приоритетных направлений для субъектов хозяйствования, осуществляющих свою деятельность в реальном времени. Информация оценки отраслевых рисков, используемая экономическим субъектом, должна быть полезна при снижении будущих угрожающих событий. Угрожающие события могут возникнуть по причине внешних источников, к примеру, резкое изменение рыночной ситуации или новые требования регулирующих органов или законодательства. Таким образом, многие субъекты хозяйствования определяют, что причинами возникновения нежелательных событий в большей степени являются внешние факторы. Внешние источники информации (публикации в средствах массовой информации и (или) рейтинговых агентств) могут быть полезны при формировании системы индикаторов. Опыт взаимодействия, мониторинг действий конкурентов или интервьюирование клиентов, заказчиков, подрядчиков, сотрудников, поставщиков может дать ключевое понимание рисковой области, с которой столкнулся субъект хозяйствования. Понимание нормативных и законодательных требований и особенностей отрасли позволит субъекту хозяйствования оперативно и заблаговременно реагировать на потенциальные угрозы. Внутренние источники информации, наоборот, в некоторых случаях бывают субъективными, но только они одни могут быть доступны в текущий период времени для прогнозирования и предотвращения воздействия возможных нежелательных событий.

Низкая вероятность того, что один ключевой индикатор риска может отражать все стороны угрожающего события. В связи с этим, необходимо отслеживать комплекс ключевых индикаторов деятельности, которые могут подавать сигналы о возникновении риска. При анализе такого комплекса необходимо учитывать степень влияния каждого индикатора деятельности в структуре риска и разделять эти индикаторы по весовым шкалам в зависимости от степени влияния. Необходимо агрегировать весь комплекс информации, самым лучшим способом обеспечивающим предварительную диагностику и предотвращение угроз. Регулярные анализ, осмысление и опыт позволяют сделать наиболее значимые выводы и повысить эффективность ключевых индикаторов риска.

Ключевые слова: агрегирование, анализ, индикатор, комплексная оценка, степень угроз, структура риска, эффективность деятельности

Отраслевые риски требуют комплексных и структурированных способов оценки, основанных как на оценке риска перспективы и роста с учетом структурного риска, риска реагирова- ния на изменения внешней среды и системном риске. Данное требование обусловлено тем, что функционируя и осуществляя бизнес-процессы во внешней среде деятельность экономических

\footnotetext{
* Статья подготовлена по результатам исследований, выполненных за счет бюджетных средств по государственному заданию Финуниверситету.
} 
субъектов подвержена конкурентному воздействию.

О.Н. Кузнецова конкуренцию определяет через соперничество «важнейшим фактором в рыночной экономике является дух соперничества, который в значительной степени определяет формы хозяйственной деятельности людей и наиболее ярко проявляется в такой экономической категории, как конкуренция» [3, 4].

В конкурентной среде формируются системные и несистемные риски, оказывающие разно уровневое влияние на экономические субъекты.

Системный риск является риском независящем от функционирования экономических субъектов и распространяет свое влияние на всех участников внешнеэкономической деятельности. Показатель системного риска определяется уровнем колебаний результатов отрасли в отношении к рынку [5].

Интегральный показатель отраслевого риска рассчитывается по следующей формуле:

$\mathrm{R}=\mathrm{F}_{\mathrm{i}} \times \beta_{\mathrm{i}}$

где $\mathrm{R}$ - интегральный показатель отраслевого риска;

$\mathrm{F}_{\mathrm{i}}$ - количество баллов, присвоенное оцениваемой отрасли по соответствующему типу риска;

$\beta_{\mathrm{i}}-$ вес типа отраслевого риска в интегральном показателе.

Интегральный показатель отраслевого риска учитывает весовые коэффициенты типа риска соответствующие весовым значениям (см. рисунок 1).

Структурный риск обладает наибольшим весовым коэффициентом, в связи с тем, что остальные типы отраслевых рисков связаны с внешними явлениями, которые стоят за пределами отраслевого рынка. Но риск чувствительности к внешней среде и системный риск в большинстве случаев оказываются решающими при принятии решений при наличии информации о макроэкономической ситуации или принятии определенных политических или экономических решений. Суммарное число всех весов факторов должно быть равно 1,00.

Веса факторов и корректирующие коэффициенты субфакторов определены в таблице 1.

Количество баллов по каждому из оцениваемых групп факторов устанавливается с использованием экспертной оценки, которая основывается на принципах минимизации риска. Зависимость баллов от риска - обратная, таким образом, чем выше балл, тем ниже будет риск. Необходимо отметить, что при наборе баллов возможно определенная их интерпретация от «+100» до «-100», в зависимости от параметра фактора риска и учета критичности всей совокупности параметров рисков. При этом «+100» отражает наиболее применимую ситуацию, т.е. несущественный уровень риска, а «-100» совер-

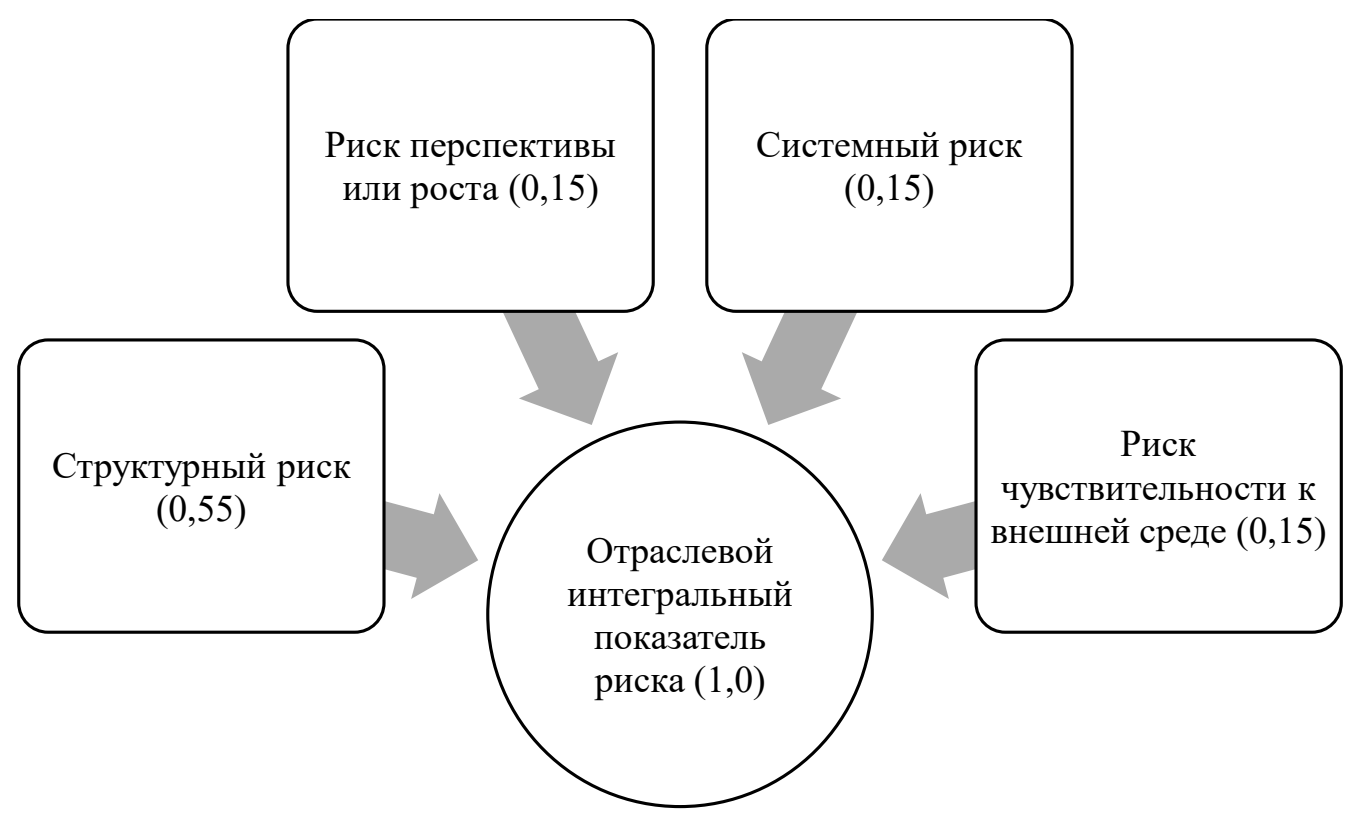

Рисунок 1. Значение весовых коэффициентов различных видов риска определяющих отраслевой интегральный показатель риска Источник: составлено авторами. 
Таблица 1. Весовые коэффициенты групп факторов риска

\begin{tabular}{|c|c|c|c|}
\hline № ח/п & Факторы & Bec & $\begin{array}{c}\text { Корректирующий } \\
\text { коэффициент }\end{array}$ \\
\hline \multicolumn{4}{|c|}{ I. Группы факторов структурного риска } \\
\hline 1. & Внутриотраслевая конкуренция & 0,30 & - \\
\hline 1.1. & Ценовая конкуренция & - & 1,00 \\
\hline 1.2 . & Рыночная сила покупателей & - & 1,00 \\
\hline 1.3. & Рыночная мощь поставщиков & - & 1,00 \\
\hline 2. & Жизненный цикл отрасли & 0,25 & - \\
\hline 3. & Уровень государственной поддержки & 0,15 & - \\
\hline 3.1. & Регулирование технологий & - & 0,40 \\
\hline 3.2 . & Тарифная политика и ценообразование & - & 0,25 \\
\hline 3.3. & Система налогообложения & - & 0,20 \\
\hline 3.4 . & Зависимость от бюджетного финансирования & - & 0,15 \\
\hline 4. & Барьеры при входе в отрасль & 0,15 & - \\
\hline 5. & Сезонность & 0,05 & - \\
\hline 6. & Экспорт & 0,05 & - \\
\hline 7. & Импорт & 0,05 & - \\
\hline \multicolumn{4}{|c|}{ II. Группа факторов риска перспективы и роста } \\
\hline 8. & Вклад отрасли в валовое производство & 0,3 & - \\
\hline 9. & Динамика объема валового производства & 0,4 & - \\
\hline 10. & Финансовый результат на конец отчетного периода & 0,3 & - \\
\hline \multicolumn{4}{|c|}{ III. Группы факторов риска чувствительности к внешней среде } \\
\hline 11. & Волатильность курсов валют & 0,4 & - \\
\hline 12. & Процентная ставка & 0,3 & - \\
\hline 13. & Обеспеченность сырьем, цены на сырье & 0,3 & - \\
\hline \multicolumn{4}{|c|}{ IV. Группа факторов системного риска } \\
\hline 14. & Системный риск & 1 & - \\
\hline
\end{tabular}

Источник: составлено авторами.

шенно противоположное значение - недопустимая ситуация, наиболее рискованный подход.

Группа факторов внутриотраслевой конкуренции предусмотрена оценкой параметров в соответствии со значениями «пяти сил конкуренции» М. Портера, которые включают в себя: уровень текущей ценовой конкуренции, уровень неценовой конкуренции; рыночную силу покупателей; рыночную мощь производителей [6].

Рыночная сила покупателей получает собственную оценку при учете во внимание таких факторов, как емкость и насыщенность рынка, а также в зависимости от характера спроса.

Формирование характеристики критериев жизненного цикла в зависимости от стадии развития отрасли необходимо обратить внимание на обобщенные качественные характеристики, к примеру, высокие, стабильные или низкие темпы роста, которые могут изменяться для конкретных отраслей. Например, 1\% в год для отрасли телекоммуникации является низким темпом роста, а для добывающих отраслей, наоборот, высоким.

Применимость различных методов оценки риска в практике деятельности субъектов хозяйствования можно рассматривать с позиции основных критериев: подходит для всех этапов работы (A); применим для работы с риском не в полном объеме (B) и невозможно применять для работы (C) [2]. Отметим, что основными методами анализа и оценки рисков следует считать метод сценарного подхода и метод имитационного моделирования.

Метод сценарного подхода считается основным методом прогнозирования ситуации, помогающим выявить оценочные критерии. В основе данного метода лежат выводы экспертов, которые определяют величину и влияние идентифицированных рисков. Метод сценариев является простым, но субъективным. Данный 
Таблица 2. Характеристика возможности применения различных методов оценки в части риска субъектов хозяйствования в практике деятельности

\begin{tabular}{|l|l|l|l|}
\hline Вероятность & \multicolumn{1}{|c|}{ Последствие } & \multicolumn{1}{|c|}{ Значительные } & Катастрофические \\
\hline Очень вероятно & $\begin{array}{l}\text { Средний риск со средней } \\
\text { степенью нагрузки }\end{array}$ & $\begin{array}{l}\text { Недопустимый риск с } \\
\text { большой степенью на- } \\
\text { грузки }\end{array}$ & $\begin{array}{l}\text { Недопустимый риск с ма- } \\
\text { лой степенью нагрузки }\end{array}$ \\
\hline Вероятно & $\begin{array}{l}\text { Средний риск с большой } \\
\text { степенью нагрузки }\end{array}$ & $\begin{array}{l}\text { Высокий риск со средней } \\
\text { степенью нагрузки }\end{array}$ & $\begin{array}{l}\text { Недопустимый риск с вы- } \\
\text { сокой степенью нагрузки }\end{array}$ \\
\hline Маловероятно & $\begin{array}{l}\text { Низкий риск со средней } \\
\text { степенью нагрузки }\end{array}$ & $\begin{array}{l}\text { Высокий риск с большой } \\
\text { степенью нагрузки }\end{array}$ & $\begin{array}{l}\text { Высокий риск с малой } \\
\text { степенью нагрузки }\end{array}$ \\
\hline Почти невероятно & $\begin{array}{l}\text { Низкий риск с большой } \\
\text { степенью нагрузки }\end{array}$ & $\begin{array}{l}\text { Низкий риск с малой } \\
\text { степенью нагрузки }\end{array}$ & $\begin{array}{l}\text { Средний риск с малой } \\
\text { степенью нагрузки }\end{array}$ \\
\hline
\end{tabular}

Источник: составлено авторами.

подход можно использовать только при наличии конечных значений выбираемых критериев.

Многие практики утверждают, что более точно характеризуют процессы управления риска субъектами хозяйствования методы имитационного моделирования. Данная модель является процедурой, которая направлена на описание изучаемого объекта и повторяющие его поведенческие характеристики [1]. Процесс количественной оценки рисков более точный и более трудоемкий, основанный на использовании математической статистики.

Для определения риска используется матрица последствий и вероятностей (см. таблицу 2).

При использовании вышеприведенной ма- трицы возникают определенные преимущества, отражающиеся в простоте использования; ранжировании риска по уровням значимости. Как положительный момент следует отметить и возможность получения результатов характеризующих отдельные ситуации.

В заключении следует отметить, что комплексные и структурированные способы оценки отраслевых рисков направлены на минимизацию угроз, негативно влияющих на функционирование и развитие экономических субъектов. Правильное использование аналитической информации оценки отраслевых рисков способствует обеспечению экономическому субъекту устойчивой конкуренции.

\section{Библиографический список}

1. Бобонец А. И. Оценка рисков в деятельности промышленных предприятий // А. И. Бобонец; Центросоюз Рос. Федерации, Белгор. ун-т потребит. кооп.- Белгород: Кооп. образование, 2003.- 201 с.

2. Буянов В. Анализ рисков в деятельности предприятия // Вопросы экономики. 2004. № 8. С. 128-134.

3. Кузнецова О.Н. Управление отраслевыми рисками в целях повышения конкурентоспособности предприятия // Новый университет. 2012. № 3 (13), С. 35-40.

4. Кузнецова, О.Н. Сущность отраслевого риска и его роль в развитии экономики [Текст] / О.Н. Кузнецова // Проблемы современной экономики: материалы междунар. заоч. науч. конф. (г. Челябинск, декабрь 2011 г.). / Под общ. ред. Г.Д. Ахметовой.- Челябинск: Два комсомольца, 2011.

5. Технология внешнеторговых сделок: Учебник/ Под общ.ред. К. В. Холопова, Ю.А. Савинова. М.: ВАВТ, 2007. C. 460.

6. Томпсон А.А., Стрикленд А.Дж. Стратегический менеджмент. Искусство разработки и реализации стратегии: Учебник для вузов. М.: ЮНИТИ, 1998, с. 118.

7. Электронный ресурс: URL: http://www.rau.su/observer/N16_93/16_04.HTM. 